\title{
Antifungal activity of some Sternbergia taxa: effects on germ tube and biofilm formation
}

\author{
Banu Kaskatepe ${ }^{1}$, Betul Sever Yilmaz ${ }^{2}$, Ozlem Bahadir Acikara ${ }^{2}$, Gulcin Saltan Iscan ${ }^{2}$, \\ Josipa Vlainic ${ }^{3}$, Ivan Kosalec ${ }^{4}$
}

\begin{abstract}
${ }^{1}$ Ankara University Faculty of Pharmacy, Department of Pharmaceutical Microbiology, Ankara, Turkey, ${ }^{2}$ Ankara University Faculty of Pharmacy, Department of Pharmacognosy, Ankara, Turkey, ${ }^{3}$ Ruder Boskovic Institute, Bijenicka Cesta, Zagreb, Croatia, ${ }^{4}$ University of Zagreb, Faculty of Pharmacy and Biochemistry, Department of Microbiology, Zagreb, Croatia
\end{abstract}

\begin{abstract}
Natural products are rapidly becoming the primary sources of novel antimicrobial agents, as resistance to existing antimicrobial agents is increasing. Apart from determining the antimicrobial activity of natural products, it is also important to understand their effects on the virulence factors of microorganisms. This study aimed to determine the antimicrobial activity of Sternbergia species prevalent in Turkey and investigate their role in the inhibition of germination tube and biofilm formation, both of which are known to be important virulence factors of Candida albicans. The antimicrobial activities of the plant extracts were evaluated using bore-plate and broth microdilution method. The extracts' capacity to inhibit the formation of the germ-tube was also evaluated. The findings of our study revealed that Sternbergia lutea, Sternbergia vernalis possessed antimicrobial activities, with MIC values ranging between 0.048 $\mathrm{mg} / \mathrm{mL}$ and $0.39 \mathrm{mg} / \mathrm{mL}$. The highest antimicrobial activity was observed against Candida dubliniensis $(0.048 \mathrm{mg} / \mathrm{mL})$. While evaluating the inhibition of fungal germination activities, $S$. vernalis extract (at a concentration of $0.09 \mathrm{mg} / \mathrm{mL}$ ) was found to be the most effective against $C$. albicans ATCC 90028 strain. The results also indicated that $S$. vernalis extracts at sub-MIC levels inhibited germ tube formation and modulated the tail-length of germinated cells, both of which are important virulence factors of $C$. albicans. Furthermore, the inhibition of biofilm-formation was also investigated, and it was found that two Sternbergia spp. extracts at or below MIC levels inhibited biofilm formation.
\end{abstract}

Keywords: Antifungal activity. Biofilm inhibition. Candida albicans. Germ tube formation. Virulence factor. Sternbergia spp.

\section{INTRODUCTION}

Sternbergia spp., belonging to the Amaryllidaceae family, are represented by five species in Turkey: $S$. lutea (L.) Ker Gawl. Ex Spreng., S. colchiciflora Waldst. \& Kit., S. vernalis (Mill.) Gorer \& J.H.Harvey, S. candida B. Mathew \& T. Baytop (endemic to Turkey), and $S$. clusiana (Ker Gawl.) Ker Gawl. ex Spreng. (theplantlist. org, 2018). Sternbergia spp. hold pharmaceutical importance because of their content of biologically active compounds such as Amaryllidaceae alkaloids, which are used in the drug industry. Of them, galantamine has been used in the treatment of Alzheimer's disease,

\footnotetext{
*Correspondence: B. Kaskatepe. Department of Pharmaceutical Microbiology, Faculty of Pharmacy, Ankara University, 06100 - Tandogan, Ankara, Turkey. Phone: +90 312203 3188. E-mail: bkaskatepe@ankara.edu.tr
}

whereas lycorine has antiviral, antimalarial, analgesic, cytotoxic, and acetylcholinesterase inhibitory activities (Gabrielsen et al., 1992; Tanker et al., 1996; Campbell et al., 1998; Lopez et al., 2002; Unver, Kaya, Öztürk, 2005). The analgesic and antimicrobial activities of the extracts and alkaloids of $S$. clusiana, S. lutea and the anti-acetylcholinesterase and antioxidant activities of the five Sternbergia species prevalent in Turkey have also been reported (Unver, Kaya, Öztürk, 2005; Orhan et al., 2011). In addition to evaluating the antimicrobial activity, it is also important to investigate the effects of plant extracts on the virulence factors of microorganisms, because they are important mechanisms adopted by the microorganisms to prevent their elimination by host defense systems. Thus, this study aimed to evaluate the antimicrobial activity of Sternbergia species and document their inhibitory effect on the formation of germ 
tube and biofilms, both of which are the most important virulence factors of $C$. albicans.

\section{MATERIAL AND METHODS}

\section{Extraction of plant material}

Three Sternbergia species: S. lutea and S. vernalis were included in the study. The designations and origins of the plants are summarized in Table I. Sternbergia species were collected from different parts of Anatolia as shown in Table I. Plant species were identified by Prof. Dr.Hayri Duman from Gazi University Faculty of Science Department of Biology. Voucher specimens are kept at the Herbarium of Ankara University, Faculty of Pharmacy with their herbarium numbers (Table I).

Fifty grams of the air-dried and powdered bulbs of each of the two taxa were macerated with water at room temperature. The extracts were then filtered using filter paper and lyophilized to obtain crude extracts. Before assaying the antimicrobial activities, the lyophilized extracts were dissolved in physiological saline to obtain a final concentration of $50 \mathrm{mg} / \mathrm{mL}$.

\section{Microorganisms}

All microorganisms including Escherichia coli ATCC 10536, Staphylococcus aureus ATCC 29213, Methicillin-resistant Staphylococcus aureus MFBF 10679, Candida albicans ATCC 90028, Candida albicans FC/S MFBF 10778, Candida albicans FC/R MFBF 11100, Candida krusei ATCC 14243, Candida tropicalis ATCC 750, Candida dubliniensis CBS 7987, and Cryptococcus neoformans MFBF 10828 were obtained from stock cultures of microorganisms at the Department of Microbiology, Faculty of Pharmacy and Biochemistry, University of Zagreb, Croatia.

\section{Antimicrobial activity}

Cylinder-plate diffusion and broth microdilution assays were performed to test the antimicrobial activity of the extracts (Cazedey, Salgado, 2011). Fungal inoculums were prepared from fresh cultures of Candida spp. in Mueller-Hinton Broth (MHB). The density of the inoculums was set to $0.5 \mathrm{McF}$ arland units using a nephelometer (ATB 1550, bioMerieux, France).

Initially, the cylinder-plate diffusion method was used for the determination of inhibition zones. Inoculums of fungi were spread onto MHA plates, after which wells $(\mathrm{d}=6 \mathrm{~mm})$ were made using sterile stainlesssteel cylinders. Fifty microliters of the plant extracts $(50 \mathrm{mg} / \mathrm{mL})$ were added to the wells. The plates were kept at $4{ }^{\circ} \mathrm{C}$ for $1 \mathrm{~h}$ to accelerate the diffusion of the extracts into agar, and then were incubated aerobically at $37^{\circ} \mathrm{C}$ for $18 \mathrm{~h}$. After incubation, the diameter of inhibition zone around each well was measured and recorded. All the experiments were repeated five times and the inhibition zone diameters $(\mathrm{mm})$ were documented as mean $\pm \mathrm{SD}$.

In the second step, minimal inhibitory concentrations (MIC) of the extracts against the microbial cells were determined by serial two-fold micro-dilution method in RPMI medium supplemented with glucose (Merck, Germany) contained in 96-well microtiter plates, following the Clinical and Laboratory Standards Institute (CLSI) procedure for Candida species. The Candida cells were seeded to the wells and treated with varying concentrations of extracts. After the incubation period, 2,3-bis (2-methoxy-4-nitro-5-sulfophenyl)- $\mathrm{H}$ tetrazolium-5-carboxanilide (XTT)/menadione solution $(0.5 \mathrm{mg} / \mathrm{mL}$ XTT and $1 \mu \mathrm{M}$ menadione in acetone, at final concentrations) was added for determination of fungal cell viability and incubated further for $3 \mathrm{~h}$. Absorbance in each well was determined using a microplate reader at $490 \mathrm{~nm}$ (Labsystems UV-Visible Reader MF). After incubation, $10 \mu \mathrm{L}$ sample from each well was spread on an SDA plate and incubated at $37^{\circ} \mathrm{C}$ for $48 \mathrm{~h}$. MIC was defined as the lowest concentration of the extract that allowed no more than $20 \%$ growth of the microorganisms after re-incubation. All the experiments were repeated thrice.

\section{Germ tube inhibition assay}

The germ tube inhibition assay was performed using C. albicans ATCC 90028 strain according to Zuzarte et al. (2011) with slight modification. $N$-acetyl-D-glucosamine medium $(0.5 \% N$-acetyl-D-glucosamine (Sigma-Aldrich),

TABLE I - Location and Herbarium numbers of Sternbergia species investigated

\begin{tabular}{ll}
\hline Plant names & Location and Herbarium numbers \\
\hline Sternbergia lutea (L.) Ker Gawl. Ex Spreng. & İzmir, Torbal1-Yeniköy Metropolis ruins, 11.11.2004, AEF no.23694 \\
\hline Sternbergia vernalis (Mill.) Gorer \& J.H.Harvey & Antakya-Yayladağ, 23.04.2006, AEF no. 23793 \\
\hline
\end{tabular}


$0.5 \%$ peptone (Sigma-Aldrich), and $0.3 \% \mathrm{KH}_{2} \mathrm{PO}_{4}$, dissolved in distilled water at a final volume of $100 \mathrm{~mL}$ and filtered) was used for the assay. Thirty microliters of the inoculum suspension in physiological saline, adjusted to $2 \mathrm{McF}$ arland units $\left(6 \times 10^{8} \mathrm{CFU} / \mathrm{mL}\right)$ were added to $170 \mu \mathrm{L}$ of $N$-acetyl-D-glucosamine media containing $90 \mu \mathrm{g} / \mathrm{mL}$ (final concentration) of the Sternbergia extracts. The samples were incubated at $37^{\circ} \mathrm{C}$ for $3 \mathrm{~h}$. Using the 400x magnification of a phase-contrast microscope, at least 100 yeast cells from each sample were counted and tail length was determined using a Dinocapture software program 2.0 version 1.5.6.

\section{Biofilm inhibition assay}

For testing the inhibition of yeast biofilm formation, each well was pretreated with $250 \mu \mathrm{L}$ FBS (fetal bovine serum; Sigma Aldrich, USA). The wells were then filled with $100 \mu \mathrm{L}$ of $C$. albicans ATCC 90028 suspension at a concentration of $5 \times 10^{6} \mathrm{CFU} / \mathrm{mL}$. The plates were incubated at $37^{\circ} \mathrm{C}$ for $4 \mathrm{~h}$ to allow attachment, and then the wells were gently washed with phosphate-buffered saline (PBS). The wells containing uninoculated broth served as negative controls. The plates were covered and incubated aerobically at $37^{\circ} \mathrm{C}$ for $24 \mathrm{~h}$. All the extracts were diluted to concentrations between 0.5 and 0.03125 $\mathrm{mg} / \mathrm{mL}$ in triplicate.

Following the incubation period, each well was aspirated and washed thrice using $250 \mu \mathrm{L}$ of PBS. The plates were vigorously shaken in order to remove the non-adherent yeast cells. The remaining adherent cells were fixed with $200 \mu \mathrm{L}$ of $99 \%$ methanol per well, which was removed after $15 \mathrm{~min}$ and the plates were left to dry overnight. The plates were then stained for 5 min with $200 \mu \mathrm{L}$ of $1 \%$ crystal violet per well. Excess stain was rinsed by placing the plates under running tap water. After the plates were air-dried, the adherent cells were resuspended in $160 \mu \mathrm{L}$ of $33 \%(\mathrm{v} / \mathrm{v})$ glacial acetic acid per well. The OD of each well was measured at $570 \mathrm{~nm}$ (Multiscan plate reader, Thermo, USA) (Abdi-Ali, Mohammadi-Mehr, Agha Alaei, 2006).

\section{Statistical analysis}

The results of the inhibition of germination assay and yeast germination tail lengths were compared using one-way ANOVA followed by Dunnett's multiple comparison test (GraphPad Prism v. 5.0 demo version, GraphPad Software, La Jolla California, USA). P-values less than 0.05 were considered significant.

\section{HPLC analyses}

HPLC analyses were carried out using Agilent LC 1200 model chromatograph (Agilent Technologies, California, USA). The diode array detector (DAD) was set at wave lengths $210 \mathrm{~nm}, 214 \mathrm{~nm}, 230 \mathrm{~nm}, 254 \mathrm{~nm}, 270$ $\mathrm{nm}, 280 \mathrm{~nm}, 330 \mathrm{~nm}$ and $360 \mathrm{~nm}$ and. The chromatograms were plotted and processed using the above mentioned software. Separation was carried out using a ACE 5 C18 $(250 \mathrm{~mm} \times 4.6 \mathrm{~mm} ; 5 \mu \mathrm{m})$ column. The mobile phase was made up of $0.2 \%$ phosphoric acid in water (A), acetonitrile (B) and in gradient elution: initial $0 \mathrm{~min}, \mathrm{~A}-\mathrm{B}(90: 10$, $\mathrm{v} / \mathrm{v})$; then $0-20 \mathrm{~min}$, linear change from $\mathrm{A}-\mathrm{B}(90: 10, \mathrm{v} / \mathrm{v})$ to $\mathrm{A}-\mathrm{B}$ (75:25); and 20-25 min isocratic elution is from A-B (0:100). The flow rate was $1 \mathrm{ml} / \mathrm{min}$ and column temperature was maintained at $40^{\circ} \mathrm{C}$. The sample injection volume was $10 \mu \mathrm{L}$.

All tested Sternbergia solutions were prepared as 1 $\mathrm{mg} / \mathrm{ml}$ by dissolving in water.

\section{RESULTS AND DISCUSSION}

Initially, antimicrobial activities of Sternbergia taxa against some microorganisms including E. coli ATCC 10536, S. aureus ATCC 29213, MRSA MFBF 10679, C. albicans ATCC 90028, A. niger ATCC 16404, and Mycobacterium fortuitum MFBF 11440 were investigated. It was observed that Sternbergia taxa were only effective against Candida. However, the antimicrobial efficacy on organisms apart from C. albicans was either very low or non-existent. Hence, the antimicrobial activities of these Sternbergia taxa were investigated against other strains of Candida, including C. albicans FC/S MFBF 10778, C. albicans FC/R MFBF 11100, C. krusei ATCC 14243, C. tropicalis ATCC 750, and C. dubliniensis CBS MFBF 11098. The extracts from all two taxa exhibited the highest activity against $C$. dubliniensis CBS MFBF 11098, with MIC values of 0.048 and $0.19 \mathrm{mg} / \mathrm{mL}$, respectively. The results of the antifungal activities of Sternbergia extracts are listed in Table II. Being members of the Amaryllidaceae family, Sternbergia species are rich in alkaloid content (Tanker et al., 1996; Çitoğlu et al., 1998). Lycorine is one of the major alkaloids found in the members of the Amaryllidaceae family. The quantification of lycorine in the bulbs of Sternbergia species was carried out using RP-HPLC external standard method in our previous study (Saltan Çitoğlu, Sever Yılmaz, Bahadır, 2008), wherein the highest content of lycorine was observed in S. lutea $(1.069 \%)$ extract. The lycorine contents in the other species were recorded as $0.543 \%, 0.43 \%$, and $0.429 \%$ for $S$. vernalis, S. candida, and S. clusiana, respectively. 
TABLE II - The antimicrobial activities of Sternbergia spp. as diameter of inhibition zone ( $\mathrm{mm})$ and MIC value (mg/mL)

\begin{tabular}{|c|c|c|c|c|}
\hline \multirow[b]{2}{*}{ Strains } & \multicolumn{2}{|c|}{ S. lutea } & \multicolumn{2}{|c|}{ S. vernalis } \\
\hline & $\begin{array}{c}\text { Inhibition zone } \\
\text { (mean } \pm \text { S.D.) }\end{array}$ & MIC & $\begin{array}{c}\text { Inhibition zone } \\
\text { (mean } \pm \text { S.D.) }\end{array}$ & MIC \\
\hline $\begin{array}{l}\text { C. albicans } \\
\text { ATCC } 90028\end{array}$ & $25 \pm 0.8$ & 0.39 & $24 \pm 0.5$ & 0.39 \\
\hline $\begin{array}{l}\text { C. albicans } \\
\text { FC/S MFBF } 10778\end{array}$ & $24 \pm 0.8$ & 0.39 & $25 \pm 0.8$ & 0.19 \\
\hline $\begin{array}{l}\text { C. albicans } \\
\text { FC/R MFBF } 11100\end{array}$ & $24 \pm 0.7$ & 0.39 & $26 \pm 0.7$ & 0.19 \\
\hline $\begin{array}{l}\text { C. krusei } \\
\text { ATCC } 14243\end{array}$ & $23 \pm 0.8$ & 0.39 & $25 \pm 0.8$ & 0.19 \\
\hline $\begin{array}{l}\text { C. tropicalis } \\
\text { ATCC } 750\end{array}$ & - & - & - & - \\
\hline $\begin{array}{l}\text { C. dubliniensis } \\
\text { CBS MFBF } 11098\end{array}$ & $30 \pm 0.7$ & 0.048 & $21 \pm 0.8$ & 0.19 \\
\hline
\end{tabular}

In current study the results of the HPLC analyses showed that water extract of the $S$. vernalis, and $S$. lutea contain mainly similar compounds in different amounts. According to the UV absorbances of the peaks it may be suggested that tested Sternbergia species may contain lycorine and galantamine when we compared to literature data (Emir et al., 2013). Therefore activities of the extracts could be related to their alkaloid content which should be proved by further studies.

Lycorine, a widespread alkaloid in Amaryllidaceae species, has been proven to possess antiviral, cytotoxic, and antimalarial activities (Sener, Orhan, Satayavivad, 2003; Liu et al., 2004). Amarbellisine, a lycorine-type alkaloid isolated from Amaryllis belladonna L., exhibits antibacterial activity against Gram-positive S. aureus. Furthermore, amarbellisine and lycorine, obtained from A. belladonna, displayed antifungal activity against $\mathrm{C}$. albicans (De Laurentis et al., 2004), while lycorine isolated from Pancratium maritimum also inhibited the growth of yeast (Kaya, 2011). Unver, Kaya and Öztürk (2005) investigated the antimicrobial effects of n-hexane, ethyl acetate, ethanol, and aqueous extracts of S. lutea ssp. lutea and S. lutea ssp. sicula using the disc-diffusion assay. They observed that all the extracts were effective against the Gram-positive S. aureus, while only some extracts were effective against Gramnegative bacteria such as E. coli and $S$. typhimurium. The extracts were ineffective against Pseudomonas and Enterobacter spp. They also reported significant inhibition of the growth of $C$. albicans, similar to our study. However, the findings of antibacterial activity in their study were in contrast to those of our study on the
Sternbergia extracts. These differences could be due to the different geographical distribution of the collected plants, which could differently influence the levels of active compounds. We have previously reported the presence of bioactive ingredient lycorine in extracts from bulbs of plants (Saltan Citoglu, Sever Y1lmaz, Bahadır, 2008). Haemantamine-, tazettin-, lycorine-, homolycorine-, crinine-, and galantamine-type alkaloids, together with lycorine, form the main constituents of Sternbergia species (Evidente et al., 2004). Hippeastrine, homolycorine-type, vittatine and 11-hydroxyvittatine, and crinine-type alkaloids from different Sternbergia species have also been reported to show antifungal activity against $C$. albicans (De Laurentis et al., 2004; Bastida et al., 2011). The antifungal activities of compounds suggested to be responsible for the antimicrobial activity of Sternbergia species, including lycorine, vittatine and 11-hydroxyvittatine, and alkaloids, have not been tested yet. The antifungal activities of a mannose-binding lectin (Saito, Misaki, 1997); polysaccharides (Evidente et al., 2004); and phenolic acids such as protocatehuic acid, 4-OH benzoic acid, vanillic acid, caffeic acid, syringic acid, $p$-coumaric acid, and ferulic acid (Nikolova, Gevrenova, 2005) have been previously evaluated in Sternbergia species.

It has been shown that the extracts of Sternbergia clusiana have relatively high levels of total phenol content (ranging from 250 to 1126 gallic acid equivalents per 100 g sample) (Mammadov, Kara, Vaizogullari, 2011), which is probably associated with their antioxidant and free radical scavenging activity. These extracts were tested for antimicrobial activity and it was observed that they 
were relatively ineffective against the majority of the tested bacteria, although some of them (leaf methanol and ethanol extract, and bulb ethanol extract) had high anticandida activity with inhibition zone diameter between 6 and $9 \mathrm{~mm}$.

The anti-candida activity is highly dependent on the compound's influence on virulence factors, which are the most important factors in the development of candidiasis. Because the transition from yeast to hypha is an important virulence factor of $C$. albicans, we assessed the ability of the extract to inhibit the germ tube formation at concentrations below the MIC, as prevalent in clinical use. The hyphal development of $C$. albicans is an important factor influencing the ability of the yeast to damage cells and progress to deep-rooted infection (Tsuchimori et al., 2000). The extent of germ tube inhibition of C. albicans ATCC 90028 following treatment with sub-inhibitory concentrations $(90 \mu \mathrm{g} / \mathrm{mL})$ of the two Sternbergia species is presented in Figure 1. The extracts of $S$. lutea was observed to insignificantly inhibit the germination process. In contrast, $S$. vernalis extract strongly inhibited germination by approximately $50 \%(\mathrm{p}=0.001)$. These findings indicated that $S$. vernalis extract at sub-MIC level is a potent inhibitor of the germination of $C$. albicans cells. Furthermore, the extract of $S$. vernalis at the same concentration also strongly reduced the tail-lengths of germinated cells of $C$. albicans (Figure 2 and Figure 3), confirming the potent anti-virulence effect of $S$. vernalis. Although all two Sternbergia taxa with antifungal activities inhibited germ tube formation of $C$. albicans with varying efficiency, $S$. vernalis extract at concentration $0.09 \mathrm{mg} /$ $\mathrm{mL}$ was found to be the most effective. The extract of $S$. vernalis strongly inhibited germination by more than $50 \%$ and also reduced the tail length, both of which are major virulence factors of Candida spp. These results are promising for the introduction of Sternbergia extracts into medicine for the treatment of Candida infections subsequent to further research and in-depth analysis of their mechanism of action.

The extracts of Sternbergia spp. were also assessed for their potential in the inhibition of biofilm formation. As shown in Figure 4, all extracts with potent antifungal activity against planktonic cells also inhibited biofilm formation of $C$. albicans. It was observed that the biofilm-inhibitory concentrations were at or below MIC values. All the two extracts tested for biofilm inhibition displayed immense potential in the reduction of biofilm mass, as evident by relatively high percentage of biofilm inhibition even at low concentrations (31.25 and 62.25 $\mu \mathrm{g} / \mathrm{mL})$.
To the best of our knowledge, this is the first study reporting the inhibition of germination and biofilm formation by extracts of Sternbergia taxa. Our results demonstrated that all extracts were potent inhibitors of Candida growth. Particularly, the extract of $S$. vernalis at sub-MIC level was a potent inhibitor of germination and biofilm formation of $C$. albicans cells, which are major virulence factors and consequences of Candida infection in living organisms and on surfaces.

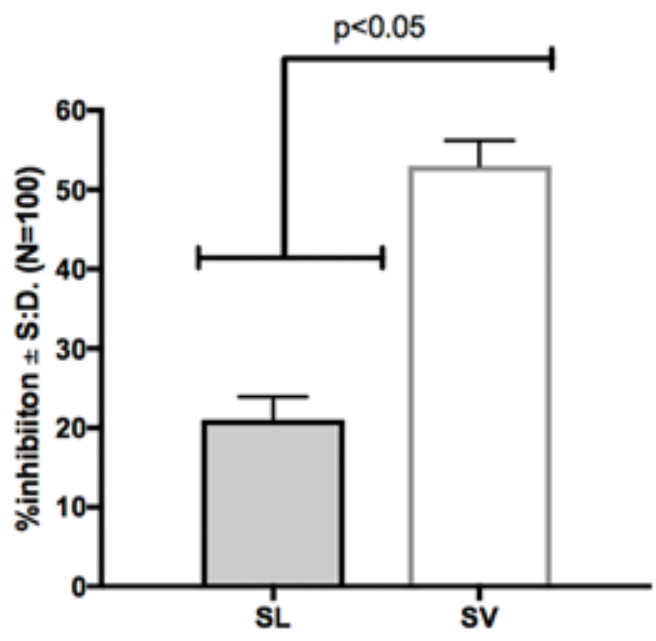

FIGURE 1 - The germ tube inhibiton percentage of C. albicans ATCC 90028 after treatment with extracts of Sternbergia spp. Legend: $\mathrm{SL}=$ Sternbergia lutea, $\mathrm{SV}=$ Sternbergia vernalis extract; All results were obtained with concentration of $90 \mu \mathrm{g} / \mathrm{mL}$.

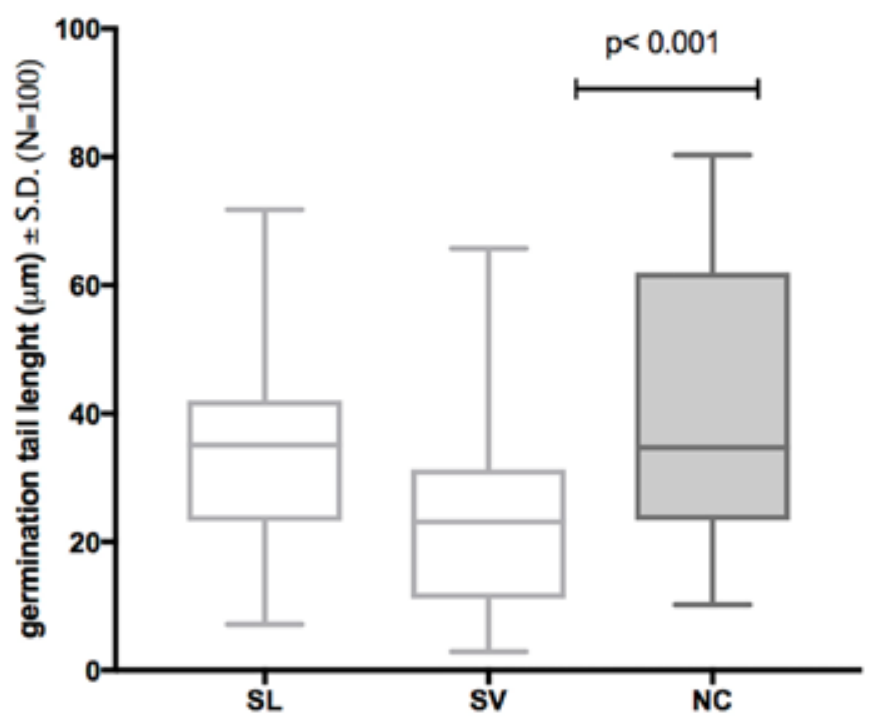

FIGURE 2 - The comparison of tail length of germinated C. albicans ATCC 90028 cells inhibited by Sternbergia spp. Extracts. Legend: $\mathrm{SL}=$ Sternbergia lutea; $\mathrm{SV}=$ Sternbergia vernalis extract; $\mathrm{NC}=$ negative control (non-treated cells). All results were obtained with concentration of $90 \mu \mathrm{g} / \mathrm{mL}$. 

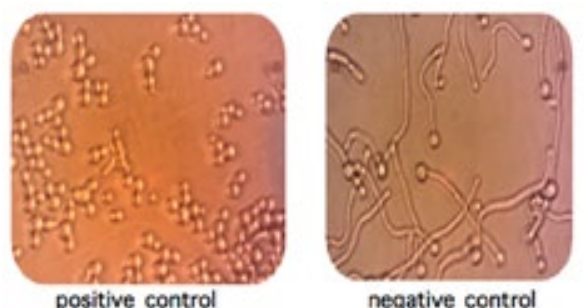

negative control

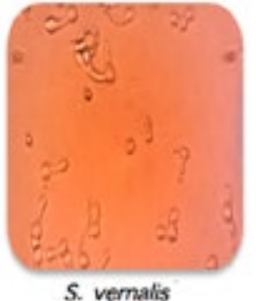

S. vemalis

FIGURE 3 - Photomicrography (400x using phase contrast microscopy) of C.albicans ATCC 90028 blastospores after $3 \mathrm{~h}$ aerobic incubation at $37^{\circ} \mathrm{C}$.

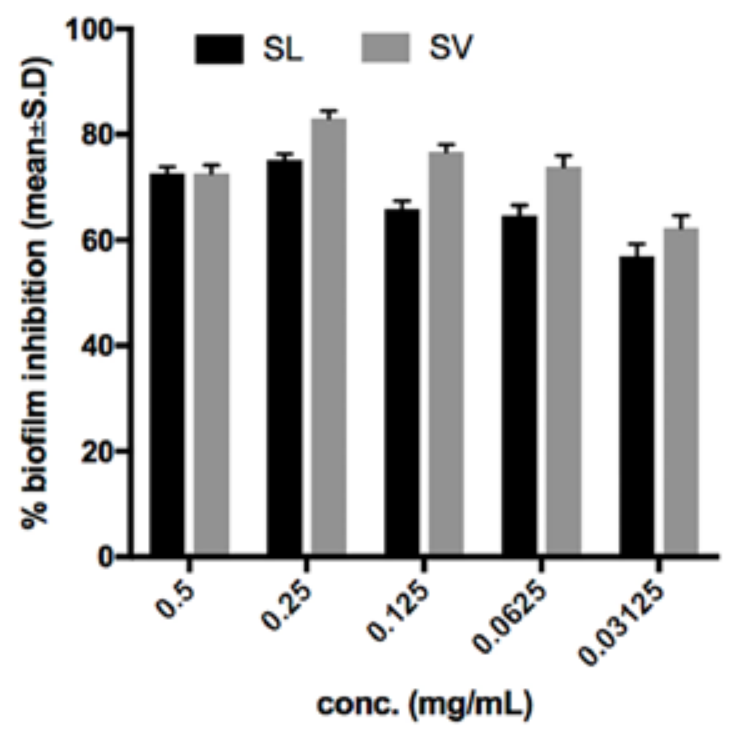

\section{CONCLUSION}

The present study showed that the extracts of two different Sternbergia species with potent antifungal activity also inhibit the germ tube and biofilm formation of C. albicans ATCC 90028 strain.

\section{ACKNOWLEDGEMENTS}

We would like to thank the Scientific and Technological Research Council of Turkey (TUBITAK-2219 post-doctoral research fellowship program) for its financial support.

\section{CONFLICT OF INTEREST}

The authors report no conflict of interest.

\section{REFERENCES}

Abdi-Ali A, Mohammadi-Mehr M, Agha Alaei Y. Bactericidal activity of various antibiotics against biofilm- producing Pseudomonas aeruginosa. Int J Antimicrob Agents. 2006;27(3):196-200.

FIGURE 4 - The percentage of biofilm inhibition of $C$. albicans ATCC 90028 by Sternbergia spp. Extracts.

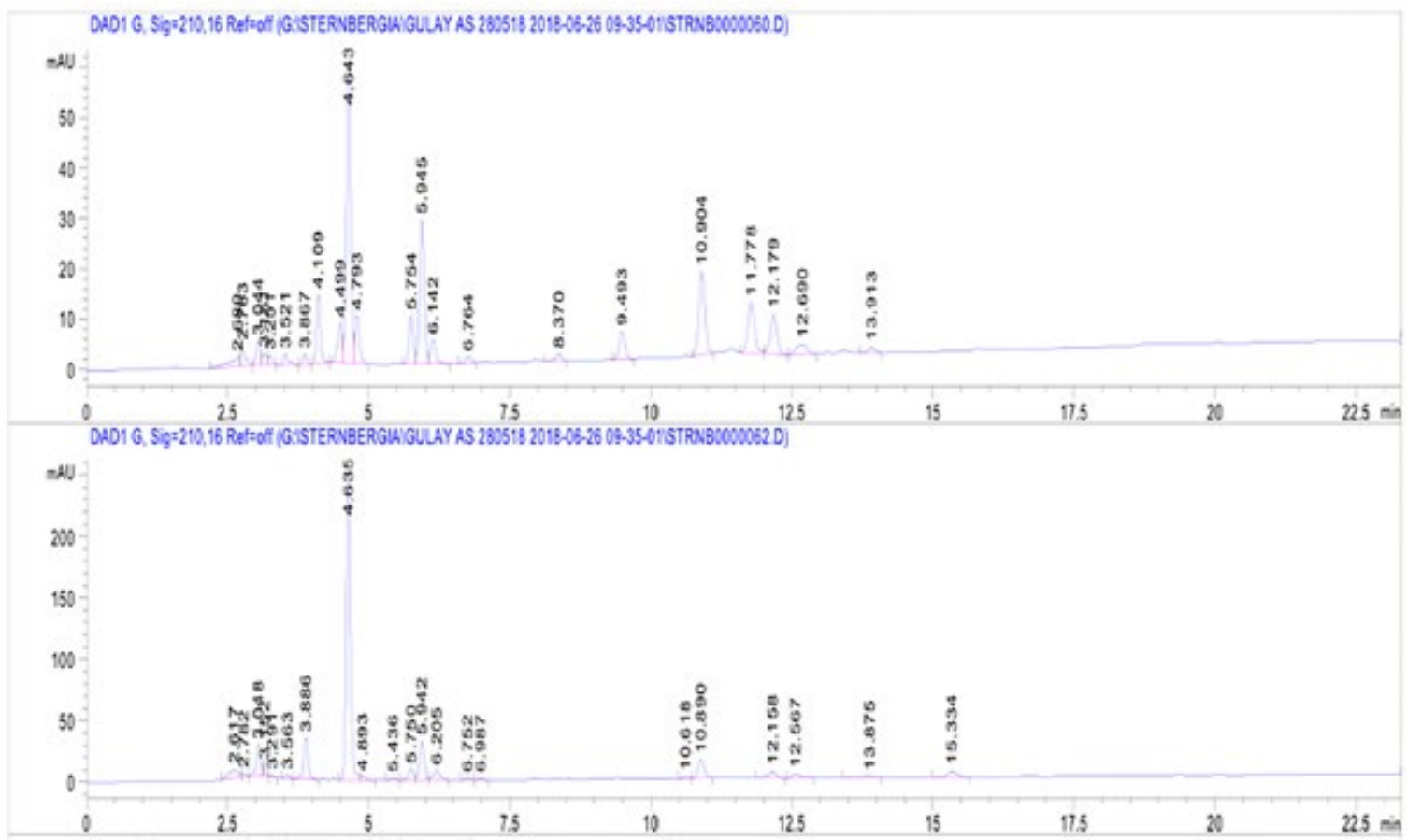

FIGURE 5 - HPLC chromatogram of S. vernalis (a), S. lutea (b). 
Bastida J, Berkov S, Torras L, Pigni Nb, Andrade JP, Martinez V, Codina C, Viladomat F. Chemical and Biological Aspects of Amaryllidaceae Alkaloids. Recent Advances in Pharmaceutical Sciences, Ed. Torrero Dm. India: Ransworld Research Network; 2011. p. 62-100.

Campbell WE, Nai JJ, Gammon DW, Bastida J, CodinaC, Viladomat F, Smith PJ, Albrecht CF. Cytotoxic and antimalarial alkaloids from Brunsvigia littoralis. Planta Med. 1998;64(1):91-93.

Citoglu G. Alkaloids of Sternbergia candida Mathew \& T. Baytop. J Fac Pharm Gazi. 1998;15(2):93-98.

De Laurentis N, Rosato A, Vitali C, Leone L, Milillo MA. Activity of lycorine extracted from Pancratium maritimum on growth of same yeast strains. Rivista Italiana EPPOS. 2004;38:19-23.

Cazedey ECL, Salgado HRN. Development and validation of a microbiological agar assay for determination of orbifloxacin in pharmaceutical preparations. Pharmaceutics. 2011;3(3):572581.

Evidente A, Andolfi A, Abou-Donia AH, Touema SM, Hammoda HM, Shawky E, Motta A, et al. (-) Amarbellisine, a lycorinetype alkaloid from Amaryllis belladonna L. growing in Egypt. Phytochemistry. 2004;65(14):2113-8.

Emir A, Çiçek Polat D, Kaya GI, Sarıkaya B, Onur MA, Ünver Somer N. Simultaneous determination of lycorine and galanthamine in galanthus woronowii by HPLC-DAD. Acta Chromatograph. 2013:25(4):755-764.

Gabrielsen B, Monath TP, Huggins JW, Kefauver DF, Pettit GR, Groszek G, Hollingshead M, Kirsi JJ, Shannon WM, Schubert EM, Dare J, Ugarkar B, Ussery MA, Phelan MJ. Antiviral (RNA) Activity of selected Amaryllidaceae Isoquinoline Constituents and Synthesis of Related Substances. J Nat Prod. 1992;55(11):1569-81.

Kaya GI. Sternbergia_Waldst. \&KIT. Türlerinin kimyasal bileşikleri ve biyolojik aktiviteleri. Marmara Pharm J. 2011;15(2):52-7.

Liu J, Hu WX, He LF, Ye M, Li Y. Effects of lycorine on HL-60 cells via arresting cell cycle and inducing apoptosis. FEBS Lett. 2004;578(3):245-50

Lopez S, Bastida J, Viladomat F, Codina C. Acetylcholinesterase inhibitory activity of some Amaryllidaceae alkaloids and Narcissus extracts. Life Sci. 2002;71(21):2521-29.
Mammadov R, Kara Y, Vaizogullari V. Study on Phenolic Content, Antioxidant and Antimicrobial Effects of Sternbergia clusina. Asian J Chem. 2011;23(12):5280-5284.

Nikolava M, Gevrenova R. Determinaton of phenolic acids in Amarllidaceae species by high performance liquid chromatography. Pharm Biol. 2005;43(3):289-291.

Orhan IE, Sever Yilmaz B, Altun ML, Saltan G, Sener B. Anti-Acetylcholinesterase and Antioxidant Appraisal of the Bulb Extracts of Five Sternbergia Species. Rec Nat Prod. 2011;5(3):193-201.

Saito K, Misaki A. Goldstein IJ Purification and characterization of a new mannose-specific lectin from Sternbergia lutea bulbs. Glyoconj J. 1997;14(8):889-96.

Saltan Citoglu G, Sever Yılmaz B, Bahadır Ö. Quantitative analysis of lycorine on Sternbergia species growing in Turkey. Chem Nat Compd. 2008;44(6):826-28.

Sener B, Orhan I, Satayavivad J. Antimalarial activity screening of some alkaloids and the plant extracts from Amaryllidaceae. Phytother Res. 2003;17(10):1220-3.

Tanker M, Çitoğlu, G, Gümüşel B, Şener B. Alkaloids of Sternbergia clusiana and their analgesic effects. Int J Pharmaco. 1996;34(3):194-197.

Tsuchimori N, Sharkey LL, Fonzi WA, French SW, Edwards JE, Filler SG. Reduced virulence of HWP1-deficient mutants of Candida albicans and their interactions with host cells. Infect Immun. 2000;68(4):1997-2002.

Unver N, Kaya Gİ, Öztürk HT. Antimicrobial activity of Sternbergia sicula and Sternbergia lutea. Fitoterapia. 2005;76(2):226-29.

Zuzarte M, Gonçalves MJ, Cavaleiro C, Canhoto J, Vale-Silva L, Silva MJ, Pinto E, Salgueiro L. Chemical composistion and antifungal activity of the essential oils of Lavandula viridis L'Hér. J Med Microbiol. 2011;60(Pt 5):612-18.

Received for publication on $30^{\text {th }}$ March 2017 Accepted for publication on 30th September 2018 